Bài báo khoa hoc

\title{
Nghiên cứu xây dựng bản đồ hiểm hoạ xâm nhập mặn vùng đồng bằng ven biển Nam Định và Thái Bình
}

\author{
Nguyễn Văn Đào1, Vũ Thanh Tú ${ }^{2}$, Trần Hồng Thái ${ }^{3}$, Nguyễn Mai Đăng 2,4* \\ ${ }^{1}$ Liên đoàn khảo sát khí tượng thuỷ văn, Tổng cục Khí tượng Thuỷ văn; \\ daotvmt@gmail.com \\ ${ }^{2}$ Khoa Kỹ thuật tài nguyên nước, Trường Đại học Thuỷ lợi; vutu@tlu.edu.vn \\ ${ }^{3}$ Tổng cục Khí tượng Thuỷ văn; tranthai.vkttv@gmail.com \\ ${ }^{4}$ Trung tâm Đào tạo Quốc tế, Trường Đại học Thuỷ lợi; dang@ @lu.edu.vn \\ *Tác giả liên hệ: dang@tlu.edu.vn; Tel.: +84-989551699 \\ Ban Biên tập nhận bài: 18/5/2021; Ngày phản biện xong: 1/7/2021; Ngày đăng bài: \\ 25/8/2021
}

Tóm tắt: Sự phát triển kinh tế, xã hội và khai thác tài nguyên trên lưu vực sông Hồng-Thái Bình cùng với biến đổi khí hậu và nước biển dâng đã tác động rất lớn tới dòng chảy, biến đổi lòng dẫn và xâm nhập mặn $(\mathrm{XNM})$ ở hạ lưu. Vì vậy, đã có các nghiên cứu về XNM nhưng chỉ xét được trên các dòng sông chính. Nghiên cứu này muốn phân tích chi tiết hơn, tính toán XNM đến từng xã thông qua mô phỏng hệ thống sông và cống lấy nước vào kênh nội đồng, và xây dựng bản đồ nguy cơ XNM. Nghiên cứu sử dụng tài liệu khí tượng thuỷ văn từ năm 1990 đến 2019 và ứng dụng mô hình MIKE 11 để mô phỏng hệ thống thuỷ động lực và khuếch tán mặn trên toàn bộ mạng sông Hồng-Thái Bình. Các kịch bản XNM đã được thiết kế theo tần suất triều và nước biển dâng, đánh giá khả năng XNM đến từng xã vùng ven biển Nam Định và Thái Bình. Kết quả nghiên cứu cho thấy 96/123 các xã ven biển Nam Định đều ở cấp hiểm họa mặn cao (> 4\%o), trong khi các xã ven biển ở Thái Bình có nguy cơ thấp hơn và chủ yếu $<2 \%$. Việc mô phỏng XNM chi tiết đến từng xã sẽ giúp cho các địa phương chủ động trong việc phòng, chống và giảm nhẹ thiệt hại do hạn mặn gây ra, đồng thời cũng có các giải pháp tận dụng khai thác các lợi ích từ XNM.

Từ khóa: MIKE 11; Khuếch tán; Nước biển dâng; Nguy co; Truyền mặn.

\section{Mở đầu}

Xâm nhập mặn (XNM) là bài toán phức tạp, diễn ra từ từ, trong một khoảng thời gian tương đối dài ở các vùng cửa sông ven biển. Các nguyên nhân chính gây ra XNM có thể đề cập tới như: hạn hán, suy giảm dòng chảy từ thượng lưu, khai thác nước ngầm quá mức, biến đổi khí hậu $(\mathrm{BĐKH})$ và nước biển dâng $(\mathrm{NBD})[1-4]$. XNM có ảnh hưởng rất lớn đến các hoạt động phát triển kinh tế xã hội, đặc biệt là các ngành sản xuất nông nghiệp, nuôi trồng thuỷ hải sản, công nghiệp và đời sống $[1,5-10]$. Theo số liệu thống kê gần đây, tình hình thiệt hại do XNM ngày càng trở lên nghiêm trọng. Vì vậy, việc nghiên cứu và đánh giá những rủi ro do XNM theo các kịch bản ngày càng trở lên cấp thiết để từ đó đề ra những biện pháp giảm thiểu và ứng phó kịp thời. Trong những năm gần đây, dưới tác động của $\mathrm{BĐKH}$ và NDB các nghiên cứu về XNM ở Việt Nam đang rất được quan tâm và đã được thực hiện trên các hệ thống sông lớn như hệ thống sông Hồng-Thái Bình, sông Cửu Long, sông Mã, sông Cả, sông Vệ, sông Vu Gia-Thu Bồn, sông Đồng Nai, sông Sài Gòn, sông Tiền Giang, sông Ray, sông Cỏ May,...[11-21]. Nhìn chung các nghiên cứu này đã chỉ ra diễn biến XMN dọc 
theo các tuyến sông, xác định danh giới xâm nhập của mặn theo một số các kịch bản tính toán riêng lẻ và chưa đánh giá nguy cơ và rủi ro do XNM.

Có thể nhận thấy trong các nghiên cứu về XMN trên các hệ thống sông thì nghiên cứu XNM trên Đồng bằng sông Hồng-Thái Bình (ĐBSH-TB) được chú ý hơn [22-23]. Xuất phát từ việc nghiên cứu các mạng sông đơn lẻ hoặc trong phạm vi giới hạn vùng nhỏ (cấp huyện, tỉnh) [24-26] cho đến nay các nghiên cứu đã xét đến tính hệ thống của các sông với phạm vi rộng hơn có tính khu vực (liên tỉnh) [23]. Các kết quả nghiên cứu đã chỉ ra được XNM ứng với dòng chảy có tần suất thấp hoặc theo các cấp lưu lượng tại thượng lưu trong trường hợp có và chưa có tác động của $\mathrm{B} Đ K H$. Tuy nhiên, việc đánh giá XNM chỉ xét đến một số giá trị lưu lượng tại thượng lưu ứng với một số trị số nhất định và tính trong thời gian ngắn nên chưa phản ánh được tác động của xâm nhập mặn đến nhu cầu sử dụng nước qua các thời kỳ. Để đánh giá về XNM ở ĐBSH-TB phục vụ cho sản xuất nông nghiệp và nuôi trồng thủy sản một số nghiên cứu đã đánh giá được diễn biến dòng chảy và XNM theo các phương án vận hành các hồ chứa Sơn La, Hòa Bình, Thác Bà và Tuyên Quang. Xác định được khả năng lấy nước của các công trình chính trên hệ thống phục vụ sản xuất nông nghiệp và các ngành kinh tế trong vùng ứng với các phương án tính toán $[1,5]$. Nhìn chung, XNM ở ĐBSH-TB đã được nghiên cứu thông qua một số đề tài khoa học các cấp. Tuy nhiên, do tính chất phức tạp của XNM trong khu vực nên cần thiết phải có các nghiên cứu đa dạng hơn để giải quyết những vấn đề còn bỏ ngỏ với các tính toán, phân tích cụ thể. Từ đó mới có các câu trả lời phù hợp, đáp ứng tốt hơn yêu cầu của thực tiễn.

Mặc dù các nghiên cứu XNM trên ĐBSH-TB cũng đã xây dựng nhiều kịch bản mô phỏng và thành lập các bản đồ danh giới XMN ứng với độ mặn $1(\%)$ hoặc $4(\% 0)$ theo các hệ thống sông [2, 22-23]. Tuy nhiên, các bản đồ đó thường là đơn lẻ theo từng kịch bản riêng biệt mà chưa có sự phân tích tổng hợp. Bên cạnh đó các danh giới XMN được xác định theo phương pháp nội suy tuyến tính với các giá trị mặn trên sông mà chưa xét đến khả năng xâm nhập nội đồng nên các bản đồ này phản ánh rõ những hạn chế khi xem xét cho một khu vực cụ thể. Kịch bản $\mathrm{B} Đ K H$ và Nước biển dâng mới cập nhật cũng chưa được xét tới. Nhằm mục đích nghiên cứu khả năng XNM với các kịch bản cực đoan do triều cường và nước biển dâng cũng như xây dựng bản đồ hiểm họa (hay còn gọi là nguy cơ) xét tới từng xã trong khu vực nghiên cứu, nghiên cứu này đã thực hiện: (1) Cập nhật các dữ liệu, số liệu đo đạc mới về địa hình, lòng dẫn, số liệu mặn đo đạc, các kịch bản NBD mới nhất được công bố; (2) Mô phỏng thủy lực, diễn toán XNM và xây dựng bản đồ vùng ảnh hưởng mặn theo các kịch bản khác nhau; (3) Xây dựng bản đồ hiểm họa, xác định vùng chịu ảnh hưởng của XNM.

Các phương pháp được sử dụng: (1) Phương pháp thống kê: thu thập, phân tích tần suất các chuỗi số liệu lưu lượng dòng chảy, mực nước triều và độ mặn tại các trạm đo điển hình; (2) Phương pháp phân tích hệ thống: đánh giá diễn biến triều, mặn và các tác động trên hệ thống lưu vực sông; (3) Phương pháp mô hình toán: thiết lập mô hình thủy lực, mô phỏng và diễn toán dòng chảy, mặn trên lưu vực sông Hồng-Thái Bình; (4) Phương pháp chuyên gia: tham vấn ý kiến của các chuyên gia và xây dựng kịch bản mô phỏng. Xét theo không gian, phạm vi mô phỏng thủy lực được thực hiện trên toàn hệ thống từ hạ lưu sông Đà, sông Thao, sông Lô và các nhánh sông ở phần thượng lưu lưu vực sông Thái Bình đến cửa ra của lưu vực sông Hồng-Thái Bình. Bản đồ hiểm họa do XNM được thiết lập cho các huyện thường xuyên chịu tác động của XNM thuộc tỉnh Nam Định và Thái Bình. Xét về thời gian: ngoài các kịch bản tính toán theo tần suất triều thiết kế, nghiên cứu đã xét tới kịch bản NBD năm 2025, 2030 và 2050 theo tài liệu của Bộ Tài nguyên và Môi trường công bố năm 2016 [27].

\section{Phương pháp nghiên cứu và tình hình xâm nhập mặn khu vực nghiên cứu}

\subsection{Tình hình xâm nhập mặn khu vục nghiên cưu}

Lưu vực sông Hồng-Thái Bình phần nằm ở Việt Nam có diện tích là $86.680 \mathrm{~km}^{2}$ (Hình 1). Trong đó, vùng DDBSH-TB với 58,4\% diện tích ở mức thấp hơn $2 \mathrm{~m}$ hoàn toàn bị ảnh 
hưởng của thuỷ triều nếu không có hệ thống đê biển và đê vùng cửa sông và dọc theo các tuyến sông. Do tác dụng bồi lắng của phù $\mathrm{sa}$, cao trình vùng bãi sông ngoài đê thường cao hơn cao trình trong dòng chính từ $3-5 \mathrm{~m}$.

Sông Hồng và sông Thái Bình được nối với nhau qua sông Đuống và sông Luộc. Các phân lưu của sông Hồng-Thái Bình ở đồng bằng đã tạo thành mạng sông khá phát triển làm cho tài nguyên nước sông phân phối về các khu vực liên quan chặt chẽ với nhau.

Vào kỳ triều cường, dòng chảy sông Hồng-Thái Bình ở vùng hạ lưu chịu ảnh hưởng của thuỷ triều vịnh Bắc Bộ, mùa kiệt (từ tháng $\mathrm{X}-\mathrm{V}$ ) ảnh hưởng nhiều hơn mùa lũ (VI-IX). Sóng đỉnh triều mùa kiệt vào sâu trong nội địa $150 \mathrm{~km}$, và trong mùa lũ ảnh hưởng vào $50-100$ $\mathrm{km}$. Mực nước triều trung bình ở Hòn Dấu thường cao nhất vào đầu mùa khô (tháng $X$ là + $36 \mathrm{~cm}$ ) và thấp nhất vào cuối mùa khô (tháng III là $+7 \mathrm{~cm}$ ).

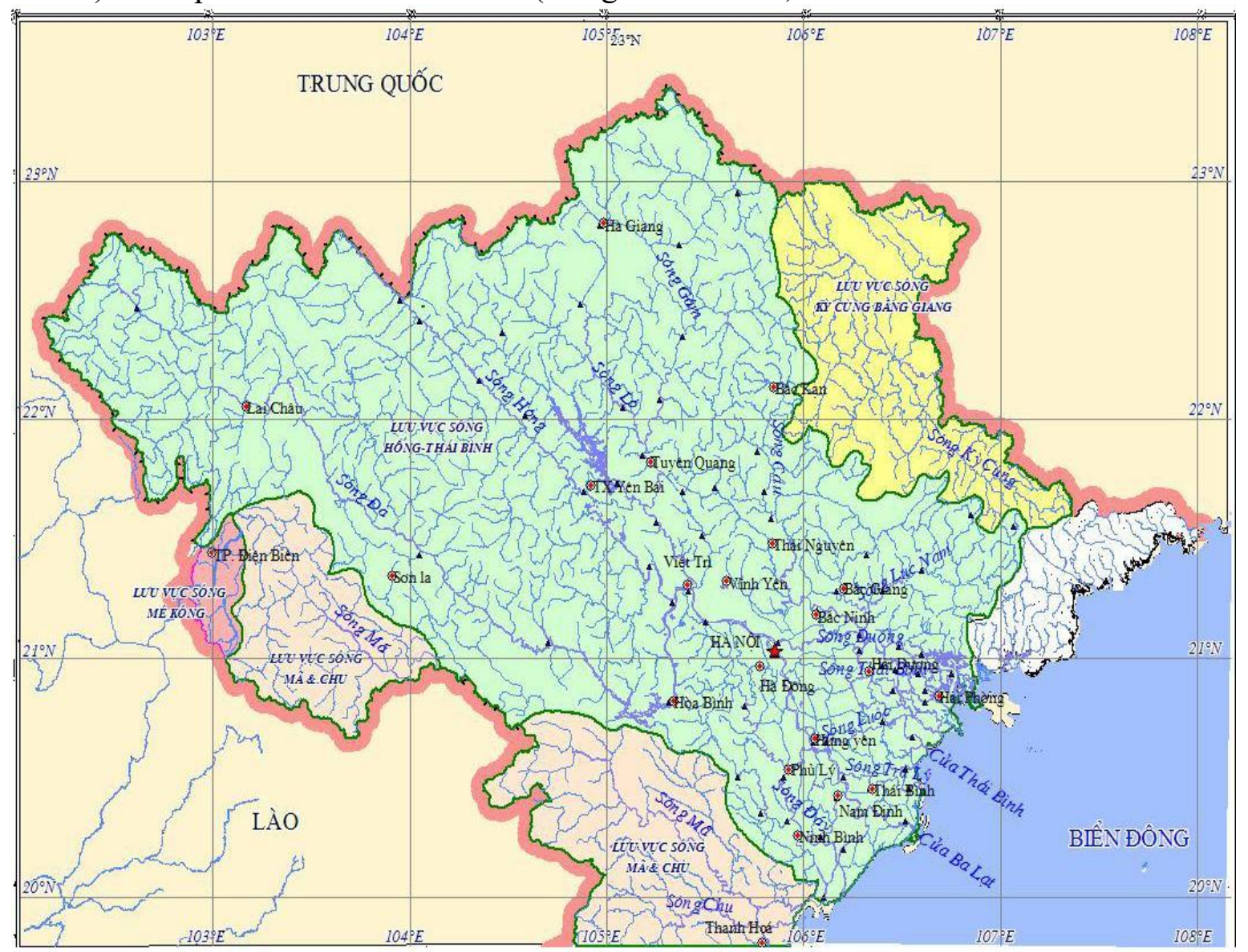

Hình 1. Lưu vực sông Hồng-Thái Bình thuộc lãnh thổ Việt Nam.

Phạm vi và mức độ nhiễm mặn nước sông phụ thuộc vào độ lớn thuỷ triều, lưu lượng nước sông từ thượng nguồn và điều kiện địa hình lòng, bãi sông. Độ mặn trong vịnh Bắc Bộ tương đối ổn định và dao động trong khoảng 32-33\%o, tại Hòn Dấu, nơi còn chịu ảnh hưởng ít nhiều của nước sông nên độ mặn trung bình vào khoảng 29-30\%o trong mùa kiệt và giảm xuống 9-23\% trong mùa lũ.

Qua số liệu thực đo tại các trạm đo, độ mặn thay đổi mạnh từ tháng XII năm trước đến hết tháng $\mathrm{V}$ năm sau, độ mặn trung bình tháng lớn nhất thường xảy ra vào tháng $\mathrm{I}$, II. Độ mặn có xu hướng tăng ở dòng chính sông Hồng và giảm phía sông Thái Bình. Khả năng bổ sung lưu lượng về mùa cạn của hồ chứa Hoà Bình đã cải thiện tình hình xâm nhập mặn. Tính trung bình nhiều năm từ chuỗi số liệu đo đạc, chiều dài xâm nhập mặn $1 \%$ xa nhất trên sông Thái Bình 13-49 km (tuỳ từng phân lưu), Ninh Cơ $36 \mathrm{~km}$, Trà Lý $51 \mathrm{~km}$, Đáy $41 \mathrm{~km}$ và sông Hồng 14-33 km. Đối với các phân lưu của hạ du sông Thái Bình dao động từ 8-49 km, với độ mặn tương ứng 4\%o và $1 \%$. 


\subsection{Phưong pháp nghiên cưu}

\subsubsection{Phương pháp mô hình toán}

Các phần mềm mô hình toán phục vụ tính toán mô phỏng quá trình xâm nhập mặn cho đến nay đã rất phát triển, cho phép các nhà nghiên cứu có thể tìm hiểu nguyên nhân, tính toán, dự báo các quá trình diễn biến xâm nhập mặn trong tương lai. Các phương pháp tính toán xâm nhập mặn đầu tiên thường sử dụng bài toán một chiều khi kết hợp với hệ phương trình Saint-Venant, với giả thiết cơ bản là các đặc trưng dòng chảy và mật độ là đồng nhất trên mặt cắt ngang. Mặc dù điều này khó gặp trong thực tế nhưng kết quả áp dụng mô hình lại có sự phù hợp khá tốt, đáp ứng được nhiểu mục đích nghiên cứu và tính toán mặn. Ưu thế đặc biệt của các mô hình loại một chiều là yêu cầu tài liệu vừa phải và nhiều tài liệu đã có sẵn trong thực tế. Trong khi đó dù các mô hình 2 chiều, 3 chiều cũng được phát triển, tuy nhiên nhiều thông số không xác định được do yêu cầu số liệu quá chi tiết hoặc/ và khối lượng tính toán lớn. Vì vậy, đa phần các nghiên cứu về xâm nhập mặn hiện nay vẫn dựa trên các mô hình 1 chiều là chủ yếu.

Hiện nay tại Việt Nam các mô hình được sử dụng để mô phỏng XMN trên các hệ thống sông rất đa dạng đã được áp dụng rộng rãi có thể kể đến như VRSAP, MEKSAL, FWQ87, SAL, SALMOD, HYDROGIS, HEC-RAS, MIKE 11 [14, 23, 28]. Kết quả được nhìn nhận khả quan và bước đầu đã thử nghiệm ứng dụng dự báo XNM. Trên thế giới, mô hình MIKE 11 là mô hình thương mại do Viện Thuỷ lực Đan Mạch xây dựng, thuộc nhóm mô hình thuỷ lực và chất lượng nước một chiều có độ tin cậy cao, thích ứng với các bài toán thực tế khác nhau. Mô hình này đã được áp dụng rất phổ biến trên thế giới cũng như tại Việt Nam để tính toán, dự báo dòng chảy, chất lượng nước và xâm nhập mặn [29-30].

a) Phương trình cơ bản cho tính toán thuỷ lực (HD)

Hệ phương trình cơ bản của MIKE 11 là hệ phương trình Saint Venant viết cho trường hợp dòng chảy một chiều trong lòng kênh dẫn hở, bao gồm:

+ Phương trình liên tục:

$$
\frac{\partial \mathrm{Q}}{\partial \mathrm{x}}+\frac{\partial \mathrm{A}}{\partial \mathrm{t}}=\mathrm{q}
$$

+ Phương trình động lượng:

$$
\alpha \frac{\partial Q}{\partial t}+\frac{\partial}{\partial x}\left(\beta \frac{\mathrm{Q}^{2}}{\mathrm{~A}}\right)+\mathrm{gA} \frac{\partial h}{\partial x}+g \frac{\mathrm{Q}|\mathrm{Q}|}{\mathrm{C}^{2} \mathrm{RA}}=0
$$

Trong đó $\mathrm{Q}$ là lưu lượng dòng chảy trên sông; q là lưu lượng nhập lưu; A là diện tích mặt cắt ướt; $h$ là mực nước sông; $x$ là chiều dài đoạn sông; $t$ là thời đoạn tính toán; $\alpha$ là hệ số động năng; $\beta$ là hệ số phân bố lưu tốc; $g$ là gia tốc trọng trường; $\mathrm{R}$ là bán kính thủy lực; $\mathrm{C}$ là hệ số Sê-di.

b) Phương trình cơ bản tính toán xâm nhập mặn (AD)

Mô đun khuếch tán $(\mathrm{AD})$ dựa trên phương trình 1 chiều về bảo toàn khối lượng của chất hoà tan hoặc lơ lửng, nó sử dụng các kết quả tính toán của mô hình thuỷ lực. Mô hình $\mathrm{AD}$ giải theo sơ đồ sai phân ẩn, mà về nguyên tắc là ổn định vô điều kiện. Phương trình khuếch tán được thể hiện qua công thức (3):

$$
\frac{\partial \mathrm{AC}}{\partial \mathrm{t}}+\frac{\partial \mathrm{QC}}{\partial \mathrm{x}}-\frac{\partial}{\partial \mathrm{x}}\left\lfloor-\mathrm{AD} \frac{\partial \mathrm{C}}{\partial \mathrm{x}}\right\rfloor=-\mathrm{AKC}+\mathrm{C}_{2} \mathrm{q}
$$


Trong đó $\mathrm{C}$ là nồng độ; $\mathrm{D}$ là hệ số khuếch tán; $\mathrm{A}$ là diện tích mặt cắt ngang; $\mathrm{K}$ là hệ số phân huỷ tuyến tính; $\mathrm{C}_{2}$ là nồng độ nguồn; $\mathrm{q}$ là lưu lượng nhập lưu; $\mathrm{x}$ là chiều dài đoạn sông, t là thời đoạn tính toán.

Phương trình phản ánh hai cơ chế vận chuyển: vận chuyển bình lưu/ đối lưu bởi dòng chảy trung bình và vận chuyển khuếch tán bởi gradient nồng độ.

Các giả thiết: vật chất và nguồn hoàn toàn xáo trộn trong mặt cắt ngang và vật chất bảo toàn theo định luật khuếch tán bậc nhất Fick, tức là vận chuyển khuếch tán tỷ lệ với gradient nồng độ.

Với những khả năng tính toán, môi trường giao diện thuận lợi cho việc thiết lập mạng lưới phức tạp của lưu vực sông Hồng-Thái Bình, nghiên cứu này đã lựa chọn mô hình MIKE 11 để phục vụ cho nghiên cứu.

\subsubsection{Phương pháp tính toán chỉ số hiểm hoạ xâm nhập mặn}

Trong bài báo này, xác định cấp độ hiểm hoạ theo cấp xã trong vùng nghiên cứu. Tham khảo các nghiên cứu [31-32], đề nghị sử dụng công thức xác định cấp độ hiểm họa mặn thông qua tổ hợp giá trị độ mặn tại từng xã. Ví dụ tại xã thứ (i) theo các kịch bản (j) có tần suất $\mathrm{P} \%$ thì tính theo công thức:

$$
S_{i}=\frac{\sum_{j=1}^{m}\left\lfloor S_{i, j}{ }^{*} w_{j}\right\rfloor}{\sum_{j=1}^{m} w_{j}}
$$

Trong đó $\mathrm{S}_{\mathrm{i}}$ là mức độ hiểm hoạ mặn tổ hợp của tất cả các kịch bản tại xã thứ $(\mathrm{i}) ; \mathrm{S}_{\mathrm{i}, \mathrm{j}}$ là giá trị độ mặn lớn nhất tại xã thứ (i) ứng với kịch bản $\mathrm{j} ; \mathrm{w}_{\mathrm{j}}$ là trọng số của kịch bản $\mathrm{j}$ (chính là tần suất xuất hiện của kịch bản $\mathrm{j}$ ); $\mathrm{m}$ là số kịch bản tính toán.

\subsection{Mô phỏng thuỷ lục và truyền mặn trên hệ thống sông Hồng-Thái Bình}

\subsubsection{Thiết lập sơ đồ mô phỏng}

Hình 2 mô tả sơ đồ mô phỏng được thiết lập gồm 7 biên trên là lưu lượng tại các trạm đo: Hòa Bình (sông Đà), Yên Bái (sông Thao), Hàm Yên (sông Lô), Chiêm Hóa (sông Gâm), Gia Bảy (sông Cầu), Chũ (sông Lục Nam) và Cầu Sơn (sông Thương); 9 biên dưới là mực nước và độ mặn tại các trạm: Như Tân (sông Đáy), Phú Lễ (sông Ninh Cơ), Ba Lạt (sông Hồng), Đông Quý (sông Trà Lý), Trung Trang (sông Văn Úc), Kiến An (sông Lạch Tray), Cửa Cấm (sông Cấm), Đồn Sơn (sông Đá Bạch) và Đông Xuyên (sông Thái Bình).

Nhìn chung, các tài liệu đo đạc thủy văn thu thập được trên mạng lưới tính toán được thu thập khá đầy đủ từ năm 1990 đến 2019. Tuy nhiên, với tài liệu mặn, do mạng lưới quan trắc độ mặn chỉ có 18 trạm với thời gian quan trắc không đồng bộ về thời gian và không liên tục, có trạm 15-20 năm, có trạm chỉ quan trắc ngắn từ 2-3 năm, thời điểm đo là vào các ngày triều cường và triều kém. Bên cạnh đó, sự phân bố các trạm không đều trên các nhánh sông cũng gây ra những khó khăn trong việc phân tích và mô phỏng.

Quá trình xâm nhập mặn diễn ra mạnh vào mùa kiệt, hầu như không có mưa hoặc lượng mưa nhỏ, do đó lượng dòng chảy sinh ra không lớn. Vì vậy, trong nghiên cứu này lượng nhập lưu khu giữa được bỏ qua trong các kịch bản tính toán. Các điều kiện ban đầu trong mô hình được xác định là giá trị lưu lượng, mực nước và độ mặn tại thời điểm bắt đầu tính toán, được xác định từ số liệu thực đo tại các trạm trên toàn lưu vực.

\subsubsection{Hiệu chỉnh và kiểm định mô hình}

Để mô phỏng diễn biến mặn, thì quá trình tính toán thủy lực và tính toán lan truyền mặn trong mô hình MIKE 11 diễn ra song song. Tuy nhiên, để hiệu chỉnh và kiểm định các bộ thông số thì việc hiệu chỉnh và kiểm định được thực hiện theo phương pháp thử sai với hai 
bước: (1) Hiệu chỉnh thông số modyun thuỷ lực (Hydrodynamic-HD) và (2) Hiệu chỉnh các thông số modyun truyền tải-khuếch tán (Advection Dispesion- $A D)$. Quá trình hiệu chỉnh và kiểm định nhằm xác định các thông số sao cho kết quả tính toán phù hợp nhất với giá trị thực đo, thể hiện thông qua các chỉ số đánh giá sai số NASH, hệ số tương quan và sai số tương đối trong trường hợp các giá trị đo mặn không liên tục.

a) Hiệu chỉnh và kiểm định modyun thủy lực (HD)

Để hiệu chỉnh các thông số của mô hình, nghiên cứu lựa chọn chuỗi số liệu thực đo từ 1/1-31/3/2012, kết quả hiệu chỉnh thông số nhám mô hình thuỷ lực tại các trạm kiểm tra có hệ số NASH lớn nhất đạt 0,95 tại trạm Sơn Tây (so sánh về lưu lượng dòng chảy tại trạm) và nhỏ nhất đạt 0,62 tại trạm Trực Phương (so sánh về mực nước tại trạm). Việc kiểm định bộ thông số được thực hiện với chuỗi số liệu thực đo từ 1/1-31/3/2008, kết quả chỉ số NASH cho thấy tại một số trạm có thể đạt trên 0.8 (trạm Sơn Tây, Hà Nội, Ghềnh Gà) và có trạm chỉ đạt mức 0,60 (trạm Quyết Chiến). Nhìn chung tại 15 trạm kiểm tra, chỉ số NASH tại các trạm kiểm tra dao động trong khoảng từ $0,62-0,95$ trong cả hai quá trình hiệu chỉnh và kiểm định, tuy nhiên đa phần các trạm đều có chỉ số lớn hơn 0,8 . Có thể nhận định được rằng bộ thông số nhám đã cho kết quả như trên là khá tốt. Sự xuất hiện đỉnh triều xảy đồng pha, hầu hết tại các vị trí kiểm tra đều tương đối phù hợp giữa tính toán và thực đo. Vì vậy, mô hình đảm bảo độ tin cậy để tính toán các kịch bản.

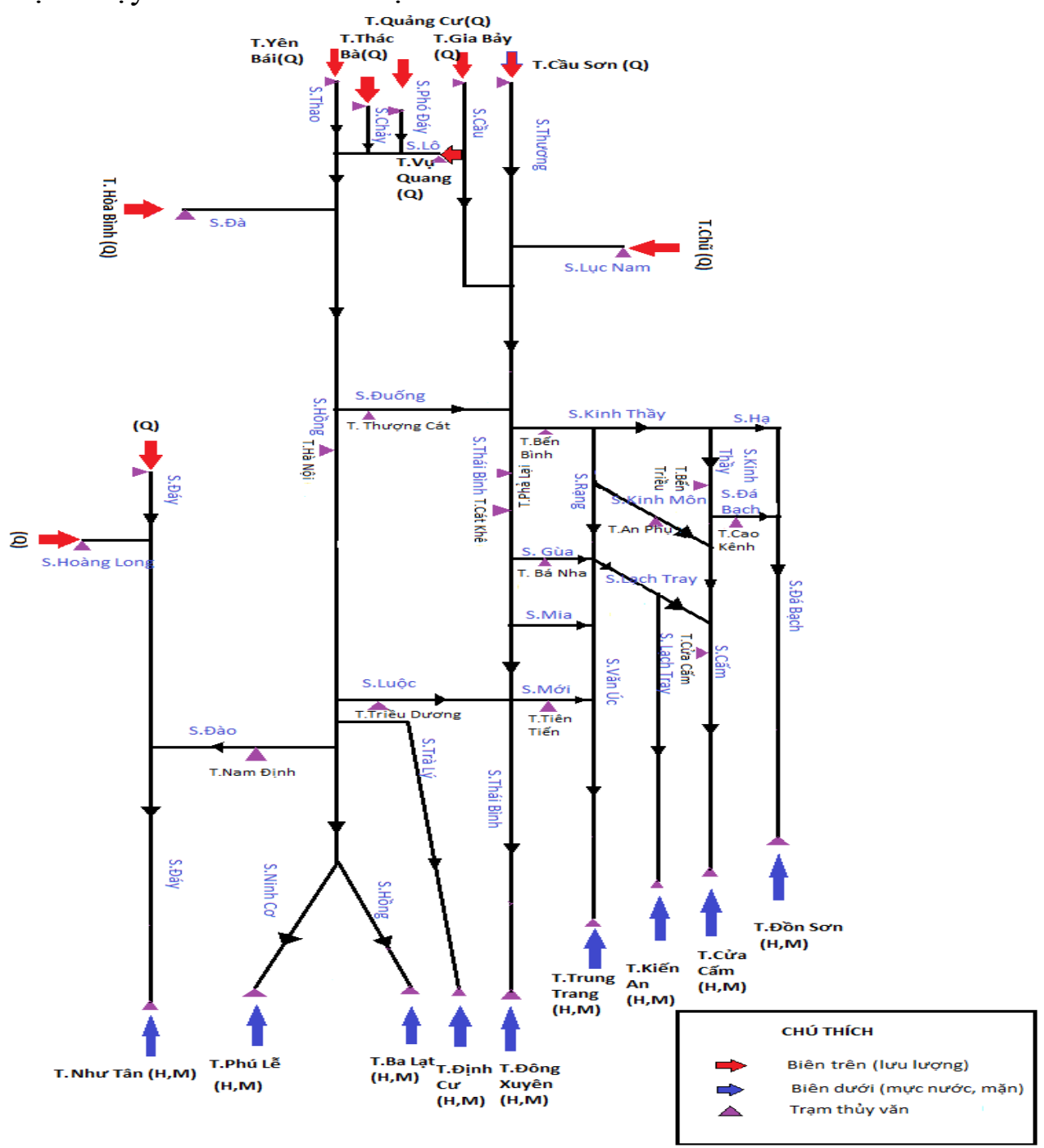

Hình 2. Sơ đồ mô phỏng thuỷ lực 1 chiều và khuếch tán mặn. 
b) Hiệu chỉnh và kiểm định modyun truyền tải-khuếch tán (AD)

Thông số khuếch tán (hệ số khuếch tán) là thống số để hiệu chỉnh và kiểm định mô hình. Đơn vị độ mặn là \%o, hoặc PSU (Practical Salinity Units), hoặc ppt (part per thounsand). Các thông số modyun truyền tải-khuếch tán cũng được xác định theo phương pháp thử dần. Tuy nhiên, việc đo mặn tại các trạm trên lưu vực sông Hồng không diễn ra liên tục, chỉ tập trung vào các ngày triều cường và triều kém trong tháng, do đó để đánh giá sự phù hợp của các thông số mô hình $\mathrm{AD}$, nghiên cứu chỉ dựa trên số liệu đo đạc tại các thời điểm đo, so sánh giá trị thực đo và tính toán tại các trạm kiểm tra có đủ số liệu. Các kết quả so sánh giữa thực đo và tình toán tại 4 vị trí cống lấy nước và 6 trạm điển hình có tài liệu đầy đủ, cho thấy mức độ chênh lệch độ mặn dao động trong khoảng từ $0,57-2,18 \%$, tuy nhiên đa phần các trạm đều có mức độ dao động nhỏ với mức độ trung bình khoảng 0,14 (\%) trong bước hiệu chỉnh và $0,02(\%)$ trong bước kiểm định mô hình. Có thể nhận thấy với mức chênh lệch độ mặn lớn nhất đo đạc và tính toán như vậy có thể chấp nhận được để thực hiện mô phỏng trong các kịch bản tiếp theo.

\subsection{Xây dựng các kịch bản mô phỏng}

Bản đồ hiểm họa do xâm nhập mặn được xây dựng dựa trên sự tổ hợp kết quả xâm nhập mặn từ các kịch bản tính toán theo mực nước triều ứng với các tần suất xuất hiện kết hợp với NBD.

\subsubsection{Nhóm kịch bản tần suất triều $(\mathrm{P} \%)$}

Quá trình lưu lượng tại các trạm biên trên được giả thiết là đồng nhất giữa các kịch bản tính toán. Quá trình triều tại các trạm biên dưới là thay đổi theo 7 kịch bản ứng với các tần suất xuất hiện: $\mathrm{P}=1 \% ; 3 \% ; 5 \% ; 10 \% ; 15 \% ; 20 \%$; và $25 \%$.

Thu thập chuỗi số liệu thực đo mực nước triều 1990-2019 và số liệu mặn 2000-2019 để tính toán các biên triều, mặn. Chọn thời kỳ kiệt từ tháng I đến tháng III để mô phỏng. Sử dụng phương pháp Person III để xác định các đặc trưng triều thiết kế theo các tần suất xuất hiện $\mathrm{P} \%$. Quá trình triều năm 2005 có các đặc trưng thống kê xấp xỉ trung bình nhiều năm nên được chọn làm năm điển hình. Từ các trị số thiết kế và quá trình triều điển hình tiến hành thu phóng để xác định các biên triều và mặn tại biên của mô hình toán.

\subsubsection{Nhóm kịch bản nước biển dâng (NBD)}

Căn cứ các kịch bản NBD của MONRE (2016), chọn 2 kịch bản điển hình là RCP4.5 và RCP8.5 theo các mốc thời gian năm 2030, 2040 và 2050 để xét sự gia tăng mực nước triều tại các biên cửa sông. Bài báo này không xét tác động của $\mathrm{B} Đ K H$ đến biến động dòng chảy ở thượng lưu.

Xét cho 5 kịch bản NBD là: (a) Thời kỳ nền; (b) RCP4.5 năm 2025; (c) RCP4.5 năm 2030; (d) RCP4.5 năm 2050 và (e) RCP8.5 năm 2050.

Để mô phỏng XNM theo các kịch bản này, giả thiết mực nước triều được xác định là trung bình của giai đoạn nền cộng với độ gia tăng của mực nước biển theo các kịch bản NBD.

Về giá trị độ mặn được xác định theo mô hình mặn của năm điển hình 2005.

\section{Kết quả và thảo luận}

Kết quả mô phỏng các kịch bản tính toán là quá trình mực nước và độ mặn tại các vị trí dọc sông trong thời đoạn tính toán, giá trị độ mặn lớn nhất tại các vị trí cống lấy nước theo các kịch bản tính toán cũng được xác định. Nhằm mục đích xác định mức độ hiểm họa của các xã trong phạm vi nghiên cứu chịu tác động của xâm nhập mặn, nghiên cứu thực hiện giả định và phân tích theo kịch bản bất lợi nhất với độ mặn lớn nhất có thể ảnh hưởng đến các xã theo giả thiết như sau: (1) Mặn xâm nhập qua hệ nước mặt (cống lấy nước) dựa trên năng 
lực lấy nước của cống; (2) Tỷ lệ cấp nước của hệ thống cấp cho các xã trong khu vực, và (iii) bỏ qua việc xem xét sự suy giảm độ mặn khi gia nhập vào hệ thống nội đồng.

\subsection{Kết quả tính toán các kịch bản tần suất triều}

Theo các kết quả mô phỏng, khoảng cách XNM (tính từ cửa sông) trên sông Đáy có độ mặn $(\mathrm{S})>4 \%$ tăng từ khoảng $24 \mathrm{~km}$ ứng với tần suất triều $(\mathrm{P}) 25 \%$, lên tới $59 \mathrm{~km}$ ứng với tần suất $1 \%$, với $\mathrm{S}<1 \%$, khoảng cách tăng từ $30 \mathrm{~km}$ đến $63 \mathrm{~km}$ theo các kịch bản tương ứng. Trên sông Ninh Cơ, do ảnh hưởng của triều tại cửa biển Thịnh Long và cửa Ba Lat trên sông Hồng, cũng như dòng chảy từ thượng lưu trên hệ thống nên hầu như toàn bộ tuyến sông đều có $S>4 \%$ trong các kịch bản mô phỏng. Đối với sông Hồng, khoảng cách có $S>4 \%$ cũng tăng từ $52 \mathrm{~km}$ đến $61 \mathrm{~km}$ và $\mathrm{S}>1 \%$ tăng từ $55 \mathrm{~km}$ đến $63,5 \mathrm{~km}$ ứng với các kịch bản tính toán. Trên sông Trà Lý, với $\mathrm{S}>4 \%$ khoảng cách XNM tăng từ $19 \mathrm{~km}$ đến $22 \mathrm{~km}$ và với $\mathrm{S}>$ $1 \%$ khoảng cách tăng từ $21 \mathrm{~km}$ đến $25 \mathrm{~km}$, tương ứng với các kịch bản tính toán. Trên sông Thái Bình, khoảng cách có $\mathrm{S}>4 \%$ tăng từ $18 \mathrm{~km}$ đến $30 \mathrm{~km}$ và $\mathrm{S}>1 \%$ tăng từ $31 \mathrm{~km}$ đến $33 \mathrm{~km}$. Nhìn chung, các hệ thống sông thuộc phạm vi tỉnh Nam Định đều chịu tác động của XNM rất cao với độ mặn lớn và khoảng cách xâm nhập cao. Ngược lại, các hệ thống sông thuộc phạm vi tỉnh Thái Bình có độ mặn và khoảng cách xâm nhập thấp hơn.

Kết quả tính toán XNM theo cấp xã cho thấy có 5 huyện Nghĩa Hưng, Trực Ninh, Xuân Trường, Hải Hậu và Giao Thủy thuộc tỉnh Nam Định có nguy cơ ảnh hưởng đời sống và đến sản xuất của người dân, tổng cộng có 123 xã bị ảnh hưởng bởi XNM với các cấp độ khác nhau dao động từ $0,1-20 \%$. Trong các kịch bản triều với $\mathrm{P} \geq 15 \%$, chỉ có khoảng 8 xã có $\mathrm{S}$ $>4 \%$, còn lại đa phần đều có $\mathrm{S}>10 \%$, trong đó có khoảng 26-45 xã có $\mathrm{S}>20 \%$ tương ứng theo các kịch bản $\mathrm{P}=10 \%$ đến $1 \%$. Đối với các kịch bản triều với $\mathrm{P} \leq 10 \%$, tất cả các xã đều có có $S>4 \%$, trong khi đó phần lớn các xã có $S \geq 15 \%$ và khoảng 50-78 xã có $S>20 \%$ o (Bảng 1).

Đối với tỉnh Thái Bình có 3 huyện Kiến Xương, Tiền Hải và Thái Thụy bị ảnh hưởng XNM, tuy nhiên không lớn như tỉnh Nam Định, tổng cộng có 120 xã đang bị ảnh hưởng. Trong tất cả các kịch bản, thì 45 xã có $S<4 \%$ và 26 xã có $S<1 \%$. Tuy nhiên số lượng các xã có $\mathrm{S}>15 \%$ cũng không nhỏ, khoảng từ 30-37 xã theo các kịch bản triều tương ứng từ $\mathrm{P}$ từ $25 \%$ đến $1 \%$ (Bảng 2 ).

Bảng 1. Thống kê số xã bị ảnh hưởng theo cấp độ mặn và 7 kịch bản tần suất triều - Nam Định.

\begin{tabular}{|c|c|c|c|c|c|c|c|}
\hline Cấp độ mặn & $P=1 \%$ & $P=3 \%$ & $P=5 \%$ & $P=10 \%$ & $P=15 \%$ & $P=20 \%$ & $P=25 \%$ \\
\hline $0,1-1 \%$ & 0 & 0 & 0 & 0 & 1 & 8 & 8 \\
\hline $1-4 \%$ & 0 & 0 & 0 & 0 & 7 & 0 & 0 \\
\hline $4-10 \%$ & 0 & 0 & 0 & 8 & 0 & 1 & 1 \\
\hline $10-15 \%$ & 2 & 10 & 10 & 5 & 8 & 14 & 18 \\
\hline $15-20 \%$ & 43 & 43 & 52 & 60 & 62 & 73 & 70 \\
\hline$>20 \%$ & 78 & 70 & 61 & 50 & 45 & 27 & 26 \\
\hline Tổng & & & & 123 & & & \\
\hline
\end{tabular}

Bảng 2. Thống kê số xã bị ảnh hưởng theo cấp độ mặn và 7 kịch bản tần suất triều - Thái Bình.

\begin{tabular}{|c|c|c|c|c|c|c|c|}
\hline Cấp độ mặn & $P=1 \%$ & $P=3 \%$ & $P=5 \%$ & $P=10 \%$ & $P=15 \%$ & $P=20 \%$ & $P=25 \%$ \\
\hline $0,1-1 \%$ & 25 & 25 & 26 & 26 & 26 & 26 & 26 \\
\hline $1-4 \%$ & 17 & 17 & 19 & 19 & 19 & 19 & 19 \\
\hline 4-10\%o & 25 & 25 & 27 & 33 & 33 & 34 & 34 \\
\hline $10-15 \%$ & 16 & 17 & 12 & 7 & 8 & 11 & 16 \\
\hline 15-20\%o & 15 & 14 & 14 & 19 & 20 & 24 & 19 \\
\hline$>20 \%$ & 22 & 22 & 22 & 16 & 14 & 6 & 6 \\
\hline Tổng & & & & 120 & & & \\
\hline
\end{tabular}


Kết quả thống kê ở các bảng và bản đồ (Hình 4) chỉ ra khoảng $87 \%$ số xã thuộc 5 huyện của tỉnh Nam Định đều có nguy cơ chịu ảnh hưởng của xâm nhập mặn cao với cấp độ hiểm họa ở mức độ từ 4\%o trở lên, đặc biệt là các xã thuộc các huyện Nghĩa Hưng, Hải Hậu và Giao Thủy. Trong khi đó mức độ hiểm họa từ 4\%o trở lên ở các huyện thuộc tỉnh Thái Bình chỉ chiếm $26 \%$ và chỉ tập trung chủ yếu ở huyện Tiền Hải.
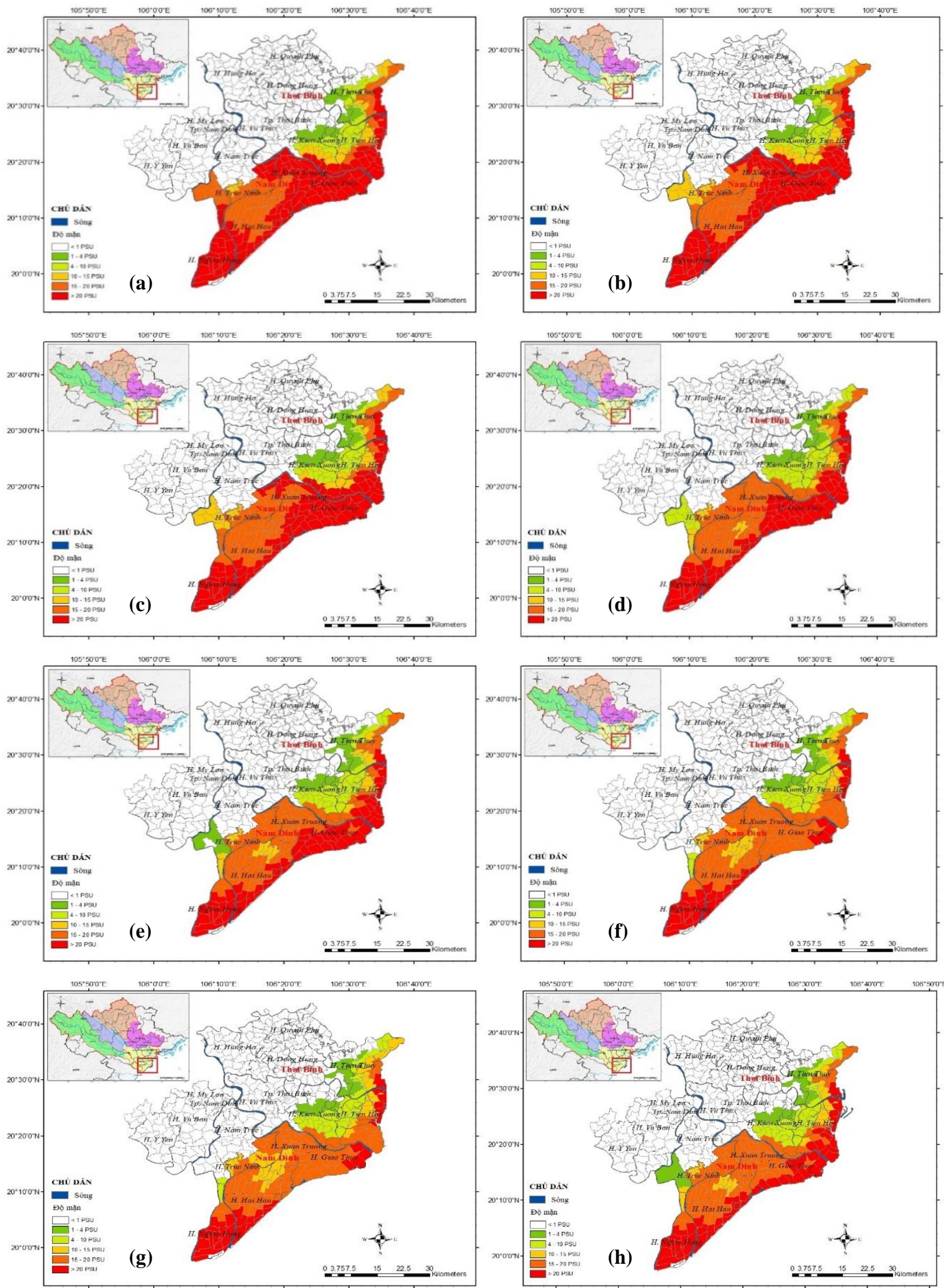

Hình 3. Phân bố mặn tại các xã theo 8 kịch bản: (a) $\mathrm{P}=1 \%$; (b) $\mathrm{P}=3 \%$; (c) $\mathrm{P}=5 \%$; (d) $\mathrm{P}=10 \%$; (e) $\mathrm{P}=15 \%$; (f) $\mathrm{P}=20 \% ;(\mathrm{g}) \mathrm{P}=25 \%$; và $(\mathrm{h})$ là tổ hợp hiềm hoạ $\mathrm{XNM}$ của 7 kịch bản tần suất triều. 


\subsection{Kết quả tính toán theo các kịch bản nước biển dâng}

Như đã trình bày về lựa chọn các kịch bản nước biển dâng, kết quả mô phỏng cho thấy khi mực nước biển dâng lên theo các kịch bản thì XNM càng sâu vào trong lục địa, tuy nhiên cũng không lớn so với kịch bản nền. Cụ thể, trên sông Đáy khoảng cách $\mathrm{S}>4 \%$ dao động trong khoảng từ $16 \mathrm{~km}$ đến $17 \mathrm{~km}$ và $\mathrm{S}>1 \%$ tăng từ $17 \mathrm{~km}$ đến $19 \mathrm{~km}$ theo các kịch bản NBD. Trên sông Ninh Cơ, khoảng cách $\mathrm{S}>4 \%$ cũng tăng dần từ $36 \mathrm{~km}$ đến toàn tuyến sông theo các kịch bản tính toán. Tương tự đối với sông Hồng, khoảng cách với $\mathrm{S}>4 \%$ tăng từ $30 \mathrm{~km}$ đến $34 \mathrm{~km}$ và $\mathrm{S}>1 \%$ tăng từ $33 \mathrm{~km}$ đến $36 \mathrm{~km}$. Trên sông Trà Lý, khoảng cách $\mathrm{S}>$ $4 \%$ tăng từ $17 \mathrm{~km}$ đến $20 \mathrm{~km}$ và $\mathrm{S}>1 \%$ tăng từ $20 \mathrm{~km}$ đến $24 \mathrm{~km}$. Trên sông Thái Bình, khoảng cách $\mathrm{S}>4 \%$ tăng từ $14 \mathrm{~km}$ đến $16 \mathrm{~km}$ và $\mathrm{S}>1 \%$ tăng từ $15 \mathrm{~km}$ đến $19 \mathrm{~km}$.

Xét về độ mặn trên các sông ảnh hưởng đến các xã trong khu vực, kết quả ở Bảng 3 cho thấy trong 123 xã vùng ảnh hưởng triều mặn thuộc tỉnh Nam Định, thì chỉ có 8 xã ở cấp độ hiểm hoạ nhỏ $(\mathrm{S}<1 \%$ ) với tất cả các kịch bản. Tuy nhiên, với cấp độ hiểm hoạ lớn hơn $(\mathrm{S}$ $>4 \%$ ) thì số xã bị ảnh hưởng tăng lên rõ rệt, cụ thể là 96 xã sẽ bị ảnh hưởng nặng nề bởi hiểm hoạ XNM do tình trạng NBD, trong đó có từ 7 đến 10 xã có $\mathrm{S}>20 \%$. So sánh hình ảnh tương tự như vậy đối với tỉnh Thái Bình, xét khu vực nghiên cứu 120 xã thì có tới 26 xã chỉ chịu hiểm hoạ XNM ở mức thấp, còn lại 73 xã có nguy cơ cao $S>4 \%$, và từ 2 đến 5 xã ở mức rất cao $\mathrm{S}>20 \%$ (Bảng 4 ). Hình 5 thể hiện các xã chịu ảnh hưởng mặn theo các cấp độ, ứng với các kịch bản NBD tương ứng.

Bảng 3. Thống kê số xã chịu ảnh hưởng theo các cấp độ mặn và các kịch bản NBD-Nam Định.

\begin{tabular}{cccccc}
\hline $\begin{array}{c}\text { Cấp độ } \\
\text { mặn }\end{array}$ & $\begin{array}{c}\text { (a) } \\
\text { Thời kỳ } \\
\text { Nền }\end{array}$ & $\begin{array}{c}\text { (b) } \mathbf{R C P 4 . 5}- \\
\mathbf{2 0 3 0}\end{array}$ & $\begin{array}{c}\text { (c) RCP4.5 } \\
\mathbf{2 0 4 0}\end{array}$ & $\begin{array}{c}\text { (d) RCP4.5 - } \\
\mathbf{2 0 5 0}\end{array}$ & $\begin{array}{c}\text { (e) RCP8.5 - } \\
\mathbf{2 0 5 0}\end{array}$ \\
\hline $0,1-1 \% 0$ & 8 & 8 & 8 & 8 & 8 \\
$1-4 \% 0$ & 10 & 0 & 0 & 0 & 0 \\
$4-10 \% 0$ & 19 & 25 & 24 & 23 & 19 \\
$10-15 \% 0$ & 48 & 52 & 52 & 52 & 55 \\
$15-20 \% 0$ & 31 & 28 & 29 & 30 & 31 \\
$>20 \%$ & 7 & 10 & 10 & 10 & 10 \\
\hline Tổng & & $\mathbf{1 2 3}$ \\
\hline
\end{tabular}

Bảng 4. Thống kê số xã chịu ảnh hưởng theo các cấp độ mặn và các kịch bản NBD-Thái Bình.

\begin{tabular}{cccccc}
\hline Cấp độ mặn & $\begin{array}{c}\text { (a) Thời kỳ } \\
\text { Nền }\end{array}$ & $\begin{array}{c}\text { (b) RCP4.5 } \\
\mathbf{2 0 3 0}\end{array}$ & $\begin{array}{c}\text { (c) RCP4.5 } \\
\mathbf{2 0 4 0}\end{array}$ & $\begin{array}{c}\text { (d) RCP4.5 }- \\
\mathbf{2 0 5 0}\end{array}$ & $\begin{array}{c}\text { (e) RCP8.5 - } \\
\mathbf{2 0 5 0}\end{array}$ \\
\hline$<1 \% 0$ & 26 & 26 & 26 & 26 & 26 \\
$1-4 \% 0$ & 24 & 21 & 21 & 21 & 21 \\
$4-10 \% 0$ & 32 & 35 & 34 & 34 & 34 \\
$10-15 \% 0$ & 22 & 20 & 21 & 21 & 21 \\
$15-20 \%$ & 14 & 16 & 16 & 16 & 13 \\
$>20 \%$ & 2 & 2 & 2 & 2 & 5 \\
\hline Tổng & & & $\mathbf{1 2 0}$ & \\
\hline
\end{tabular}




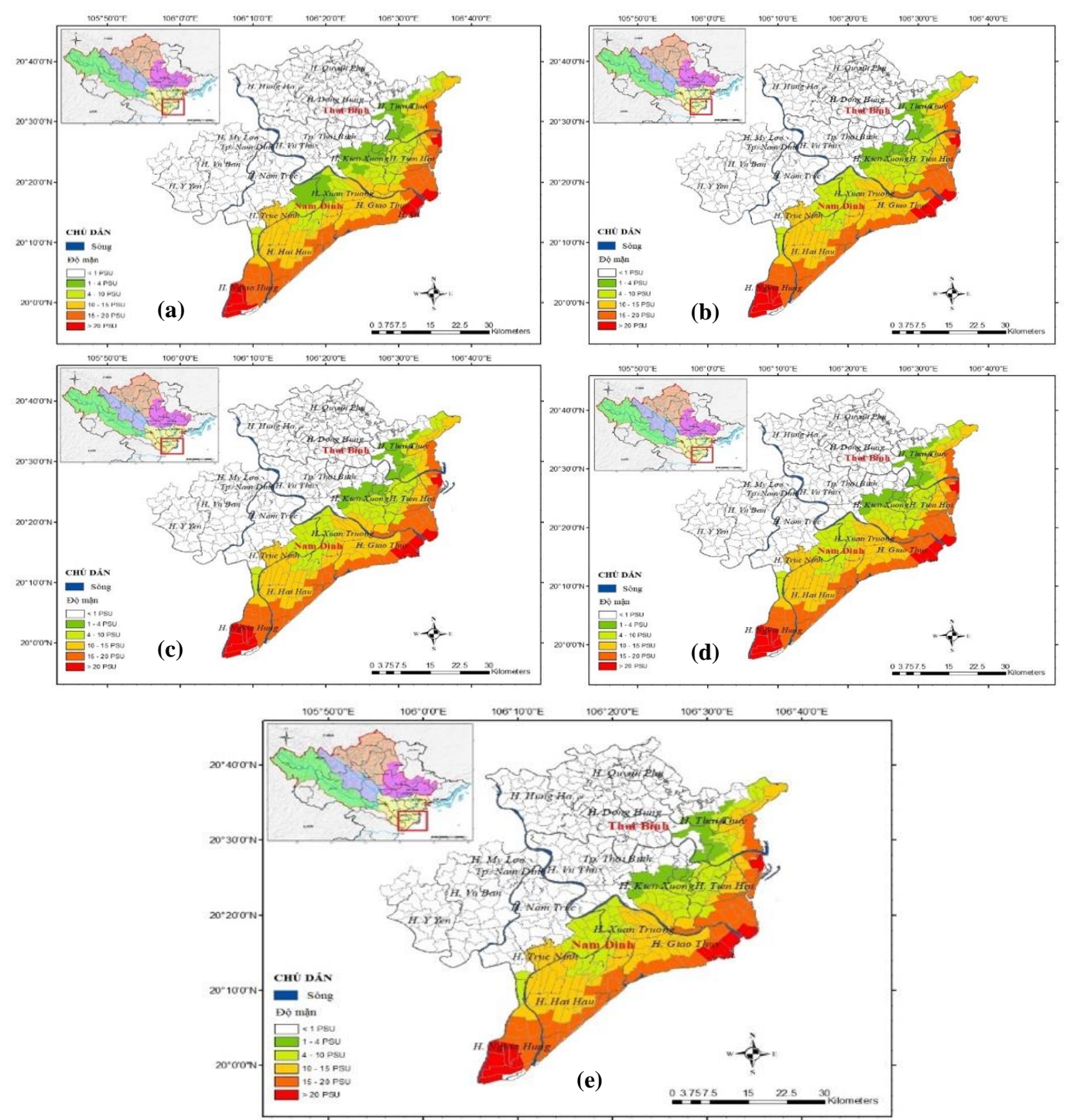

Hình 5. Hiểm hoạ XNM tại các xã theo kịch bản: (a) Thời kỳ Nền, (b) RCP4.5-2030, (c) RCP4.52040, (d) RCP4.5-2050, (e) RCP8.5-2050).

\section{Kết luận}

Xâm nhập mặn là quá trình diễn ra thường xuyên xảy ra ở các vùng cửa sông ven biển, có ảnh hưởng lớn tới các hoạt động khai thác nước ngọt trên sông phục vụ cho các hoạt động phát triển $\mathrm{KTXH}$, đặc biệt trong bối cảnh $\mathrm{BĐKH}$ và NBD. Đã có nhiều nghiên cứu về XNM trên ĐBSH-TB, tuy nhiên các nghiên cứu mới dừng lại ở việc đánh giá khả năng XNM trên hệ thống sông và xây dựng bản đồ danh giới XNM theo các kịch bản riêng lẻ mà chưa tính tổ hợp, bài báo này đã được khắc phục điều đó và đã thực hiện thành công cho khu vực nghiên cứu.

Kết quả tính toán XNM theo cấp xã cho thấy 5 huyện Nghĩa Hưng, Hải Hậu, Giao Thuỷ, Trực Ninh và Xuân Trường của tỉnh Nam Định bị ảnh hưởng lớn, và ở mức độ hiểm họa cao (> 4\%o). Mặn xâm nhập sâu vào sâu trong lục địa theo các dòng sông chính lên tới $50 \mathrm{~km}$, sông Ninh Cơ bị ảnh hưởng nhiều nhất. Khoảng $87 \%$ số xã của 5 huyện có nguy cơ chịu ảnh hưởng của XNM cao với cấp độ hiểm họa từ $4 \%$ trở lên, đặc biệt là các xã thuộc các huyện Nghĩa Hưng, Hải Hậu và Giao Thủy.

So với Nam Định thì Thái Bình có mức độ nhẹ hơn, chỉ có 3 huyện Tiền hải, Thái Thuỵ và Kiến Xương bị ảnh hưởng XNM từ $1 \%$ trở lên. Đa số các xã có $\mathrm{S}<2 \%$, và trên các dòng sông chính xâm sâu vào lục địa phạm vi $25 \mathrm{~km}$. Chỉ có khoảng $26 \%$ số xã có mức hiểm hoạ mặn $\mathrm{S}>4 \%$ và chủ yếu tập trung ở huyện Tiền Hải. 
Đối với các kịch bản NBD thì XNM trên các tuyến sông và phạm vị các xã ven biển và vùng phụ cận có lấn sâu thêm vào lục địa nhưng không nhiều, chỉ tăng thêm từ khoảng từ 1$3 \mathrm{~km}$ so với thời kỳ nền. Việc phân tích, đánh giá cụ thể cấp độ hiểm họa XNM tại các xã trên khu vực nghiên cứu, cho thấy có tính hợp lý cao hơn so với các bản đồ ranh giới XNM trước đây. Bản đồ hiểm họa cũng đem lại cái nhìn tổng quát cho phép đánh giá những khả năng tác động đến các hoạt động kinh tế xã hội và từ đó đưa ra những giải pháp thích ứng để giảm thiểu những tác động bất lợi có thể xảy ra trong tương lai.

Đóng góp của tác giả: Xây dựng ý tưởng nghiên cứu: N.M.Đ., T.H.T., N.V.Đ.; Lựa chọn phương pháp nghiên cứu: N.M.Đ., V.T.T.; Xử lý số liệu: N.V.Đ., V.T.T.; Thiết lập và ứng dụng mô hình toán thuỷ lực 1 chiều và truyền mặn trong sông: N.V.Đ., V.T.T.; Xây dựng kich bản và phân tích kết quả: V.T.T., N.V.Đ., N.M.Đ.; Viết bản thảo bài báo: N.V.Đ., V.T.T., T.H.D.; Chỉnh sửa bài báo: N.M.Đ., V.T.T., T.H.T.

Lời cam đoan: Tập thể tác giả cam đoan bài báo này là công trình nghiên cứu của tập thể tác giả, chưa được công bố, không được sao chép từ những nghiên cứu trước đây; không có sự tranh chấp lợi ích trong nhóm tác giả.

\section{Tài liệu tham khảo}

1. Trường, T.V.; Sách, B.N.; Tuấn, N.V.; Sơn, L.V. Đánh giá xâm nhập mặn vùng ven biển Bắc bộ ứng với các kịch bản cấp nước thời kỳ đổ ải vụ Đông Xuân trên hệ thống sống Hồng và đề xuất tiết kiệm nguồn nước từ các hồ chứa. Tap chi Khi tuợng Thủy văn 2019, 704, 33-48.

2. Thắng, P.T. Ảnh hưởng của biến đổi khí hậu - nước biển dâng đến xâm nhập mặn dải ven biển đồng bằng Bắc Bộ. Báo cáo tổng kết đề tài cấp Bộ, 2012.

3. Liu, H.; Peng, B.; Liao, S.; Wang, Y. The characteristics and causes of increasingly severe saltwater intrusion in Pearl River Estuary. Estuar. Coast. Shelf Sci. 2019, 220, 54-63.

4. Vĩnh, C.T. Xâm nhập mặn ở đồng bằng sông Cửu Long dưới tác động của Biến đổi khí hậu và đề xuất các giải pháp giảm thiểu. Tap chi Khí tượng Thủy văn 2013, 634, 21-24.

5. Hải, V.T. Nghiên cứu đề xuất các giải pháp thủy lợi kết hợp nông nghiệp để ứng phó với hạn hán và xâm nhập mặn tại các tỉnh ven biển đồng bằng sông Hồng. Báo cáo đề tài cấp Bộ, 2014.

6. Rahmawati, I.L.N.; Vuillaume, J.F. Salt intrusion in coastal and lowland areas of semarang city. J. Hydrol. 2013, 494, 146-159.

7. Haddout, S.; Igouzal, M.; Maslouhi, A. Modeling the effect of salt water intrusion in the Sebou River estuary (Morocco). Russ. Meteorol. Hydrol. 2017, 42, 803-811.

8. Pereira, C.S.; Lopes, I.; Sousa, J.P.; Chelinho, S. Effects of $\mathrm{NaCl}$ and seawater induced salinity on survival and reproduction of three soil invertebrate species. Chemosphere 2015, 135, 116-122. 
9. Unno, T.; Jungman, K.; Yumi, K.; Son, G.N.; Robin, B.G.; Gee, P.K.; Ji-Hoon, L.; Michael, P.S. Influence of seawater intrusion on microbial communities in groundwater. Sci. Total Env. 2015, 532, 337-343.

10. Alcérreca-Huerta, J.C.; Callejas-Jiménez, M.E.; Carrillo, L.; Castillo, M.M. Dam implications on salt-water intrusion and land use within a tropical estuarine environment of the Gulf of Mexico. Sci. Total Environ. 2019, 652, 1102-1112. https://doi.org/10.1016/j.scitotenv.2018.10.288.

11. Park, E.; Loc, H.H.; Binh, D.V.; Kantoush, S. The worst 2020 saline water intrusion disaster of the past century in the Mekong Delta: Impacts, causes, and management implications. Ambio. 2021 Online first: https://doi.org/10.1007/s13280-021-01577$\mathrm{z}$.

12. Phụng, L.N.; Phùng L.T.; Nam, N.K.; Hoàng, B.C.; Tuấn, T.X. Ảnh hưởng của biến đổi khí hậu đến xâm nhập mặn ở tỉnh Vĩnh Long. Tap chí Khi tương Thủy văn 2017, $674,8-15$.

13. Hồng, N.V.; Đông, N.P. Mô phỏng xâm nhập mặn các sông chính trên địa bàn tỉnh Bà Rịa-Vũng Tàu trong bối cảnh biến đổi khí hậu. Tap chi Khí tượng Thủy văn $\mathbf{2 0 2 1}$, 728, 67-79. https://doi.org/10.36335/VNJHM.2021(728).67-79.

14. Đại, T.H.; Thái, H.V. Nghiên cứu mô hình thủy động lực 1-2 chiều để dự báo xâm nhập mặn hạ lưu sông Mã. Tạp chí Khí tương Thủy văn 2014, 645, 1-6.

15. HIền, N.T. Đánh giá ảnh hưởng của xâm nhập mặn đến hạ lưu sông Cả trong bối cảnh biến đổi khí hậu. Tap chi Khí tượng Thủy văn 2020, 709, 13-24, https://doi.org/10.36335/vnjhm.2020(709).13-24.

16. Long, B.T.; Diệp, L.T.M. Mô phỏng sự phụ thuộc xâm nhập mặn và các yếu tố thủy văn bằng MIKE 3 - Trường hợp cửa sông Vệ, Quảng Ngãi. Tap chí Khí tượng Thủy văn 2021, 725, 1-16. https://doi.org/10.36335/VNJHM.2021(725).1-16.

17. Sơn, H.T.; Lan, V.T.T.; Tuấn, H.N. Diễn biến xâm nhập mặn vùng hạ lưu hệ thống sông Vu Gia - Thu Bồn. Tap chí Khí tương Thủy văn 2018, 686, 37-45.

18. Bảo, Đ.P. Xây dựng công nghệ dự báo dòng chảy cạn, xâm nhập mặn cho hệ thống sông Vu Gia - Thu Bồn. Tap chí Khí tương Thủy văn 2017, 682, 48-55.

19. Đào, P.T.T.; Bình, N.V. Đánh giá thực trạng và tác động của Biến đổi khí hậu đến xâm nhập mặn tỉnh Bến Tre. Tap chí Khí tượng Thủy văn 2019, 700, 12-22.

20. Phùng, N.K.; Bảy, N.T.; Kim, T.T.; Tuấn, L.N. Nguy cơ xâm nhập mặn các sông chính tỉnh Đồng Nai trong bối cảnh Biến đổi khí hậu và nước biển dâng. Tap chí Khí tương Thủy văn 2017, 678, 18-28.

21. Kim, B.H.; Sơn, T.T; Bảy, N.T.; Diễm, P.T.M.; Phùng, N.K. Nghiên cứu tính toán lan truyền mặn trên sông Sài Gòn bằng phương pháp số. Tap chí Khi tương Thủy văn 2019, 699, 17-29. 
22. Văn phòng DHI Việt Nam. Tính toán xâm nhập mặn trên các sông thuộc tỉnh Thái Bình và đề xuất giải pháp thích ứng. Báo cáo dự án, 2012.

23. Hằng, Đ.T. Xây dựng chương trình dự báo xâm nhập mặn cho khu vực Đồng bằng sông Hồng - Thái Bình. Báo cáo đề tài nghiên cứu cấp Bộ, 2010.

24. Tùng, N.B.; Đức, Đ.Đ.; Quang, T.V.; Trung, N.Đ. Đánh giá ảnh hưởng của xâm nhập mặn đến các công trình lấy nước tưới vào thời kì kiệt của sông Ninh Cơ. Tap chí Khí tuợng Thủy văn 2020, 710, 43-57. https://doi.org/10.36335/vnjhm.2020(710).43-57.

25. Thắng, Đ.Đ.; Thái, T.H.; Hòa, V.V. Đánh giá thực trạng và dự tính khả năng xâm nhập mặn cho khu vực ven biển tỉnh Thái Bình. Tap chí Khí tượng Thủy văn 2019, 699, 9-16.

26. Quang, H.N. Mô phỏng xâm nhập mặn trên sông Trà Lý theo các Kịch bản biến đổi khí hậu. Tap chí Khí tượng Thủy văn 2016, 672, 13-19.

27. MONRE. Kịch bản Biến đổi khi hậu và nước biển dâng cho Việt Nam. Nhà xuất bản Tài nguyên - Môi trường và Bản đồ Việt Nam, 2016.

28. Linh, V.T. Nghiên cứu ứng dụng mô hình hóa đánh giá xu thế của ngập lụt và xâm nhập mặn trong bối cảnh biến đổi khí hậu: nghiên cứu thí điểm tại thành phố Hồ Chí Minh. Tap chí Khi tuợng Thủy văn 2019, EME2, 98-110. https://doi.org/ 10.36335/vnjhm.2019(eme2).98-110.

29. Hải, Đ.V.; Huệ, L.T.; Trí, Đ.Q. Nghiên cứu ứng dụng mô hình hóa xây dựng phần mềm dự báo lũ, xâm nhập mặn sông Cửu Long hiển thị kết quả dự báo mặn lên Google Earth. Tap chi Khi twợng Thủy văn 2020, 710, 33-42. https://doi.org/10.36335/vnjhm.2020(710).33-42.

30. DHI. MIKE 11: A Modelling System for Rivers and Channel, Reference manual. DHI Water \& Environment, 2017.

31. Ferrari, F. The general Risk Assessment methodology. KULTURisk Project (Knowledge-based approach to develop a cULTUre of Risk prevention) Report, 2013.

32. Ranzi, R. Levee Breaches Statistics, Geotechnical Uncertainty, Residual Risks in Flood Hazard Mapping. Proceedings of $35^{\text {th }}$ IAHT congress, Chengdu, China, 2013.

\section{Development of Salinity Instrusion Hazard Maps in Coastal Plains of Nam Dinh and Thai Binh}

\footnotetext{
Nguyen Van Dao ${ }^{1}$, Vu Thanh $\mathrm{Tu}^{2}$, Tran Hong Thai ${ }^{3}$, Nguyen Mai Dang ${ }^{2,4 *}$

${ }^{1}$ Federation of Hydrometeorological Surveys, Vietnam Meteorological and Hydrological Administration; daotvmt@gmail.com

${ }^{2}$ Faculty of Water Resources Engineering, Thuyloi University; vutu@tlu.edu.vn

${ }^{3}$ Vietnam Meteorological and Hydrological Administration; tranthai.vkttv@ gmail.com

${ }^{4}$ Center for Internation Education, Thuyloi University; dang@ $@$ tlu.edu.vn
} 


\begin{abstract}
Social and economic devlopment as well natural resources exploitation in the Hong-Thai Binh River basin enclosed with climate change and sea level rise affected strongly to flow, river bed and saline intrusion in the downstream. Therefore, there are previous studies on saltwater intrusion but only on the main rivers. This paper aims to study in more detail on computing saltwater intrusion in each commune through modeling of river systems and sluices that take water into the irrigation canals, then develop risk maps of saltwater intrusion in the study area. Hydro-meteorological data from 1990 to 2019 and MIKE 11 model are used to simulate the hydrodynamic system and saline diffusion in the Red-Thai Binh River network. The saltwater intrusion scenarios are conducted according to the tidal frequency and sea level rise, and assessed the saltwater intrusion hazards in scale of each commune in the coastal areas of Nam Dinh and Thai Binh. It is showed that 96/123 coastal communes in Nam Dinh are at high salinity hazard level (> 4\%o), while the coastal zone in Thai Binh are at lower risk with mainly saline $<2 \%$. The detailed imformation of saltwater intrusion for each commune will help local authorities and farmers to be proactive in preventing, combating and mitigating damage caused by saltwater drought, in addition there are solutions to take advantage in exploiting the benefits from saline intrusion.
\end{abstract}

Keywords: MIKE 11; Diffusive; Sea level rise; Hazard; Salinity. 